\title{
A expressão do real: estética e hermenêutica das imagens
}

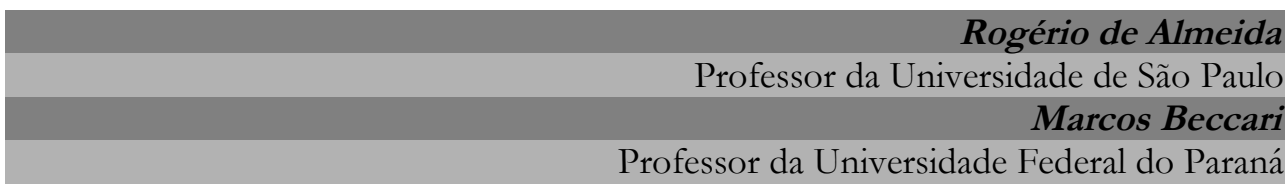

\section{Resumo}

O objetivo deste artigo é explorar a relação de complementaridade entre o real e o imaginário, com foco no aspecto estético-hermenêutico que constitui a expressividade das imagens. Partimos da problematização do estatuto epistemológico da imagem no pensamento ocidental, recorrendo a autores (Durand e Rosset) que privilegiam a imagem como expressão do real. Por fim, discutirmos a prevalência da "imagem estética", por meio da qual o mundo explicita-se como aparência de mundo no cenário contemporâneo. Por este caminho, propomos uma abordagem da imagem que possa abranger a intensidade dos fluxos afetivos e, ao mesmo tempo, a pluralidade das interpretações.

Palavras-chave: filosofia da imagem; estética; hermenêutica trágica.

\begin{abstract}
The aim of the article is to explore the relationship of complementarity between the real and the imaginary, focusing on aesthetic and hermeneutic aspects, which constitutes the expression of the images. As start, it discusses the epistemological statute of the image in occidental thought, with authors (Durand and Rosset) that consider the image as expression of the real. Finally, it discusses the prevalence of "aesthetic image", through which the world explicit itself as the appearance of the world in the contemporaneity. By this way, it proposes an approach of the images that may contain the intensity of the affective flows and simultaneously the plurality of the interpretations.
\end{abstract}

Keywords: philosophy of the image; aesthetics; tragic hermeneutics. 
Introdução

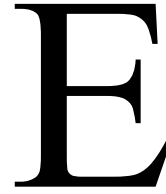

ste artigo se propõe a mostrar que a relação de complementaridade entre o real e o imaginário - contrariamente às concepções que sobrepõem um desses polos em detrimento do outro - é pautada numa dupla dimensão das imagens: estética e hermenêutica. De início, apresentamos um arrazoado sobre o estatuto epistemológico da imagem - a prevalência do olhar iconoclasta segundo o qual a imagem guarda sempre uma relação inferior à coisa que representa -, para, em contrapartida, propormos uma visada positiva da imagem, por meio das contribuições de Gilbert Durand e Clément Rosset.

Uma vez desfeita, sob um viés nietzschiano, a oposição clássica entre aparência e verdade, descrevemos as implicações de se considerar o real e o imaginário como esferas indissociáveis: toda imagem é real enquanto imagem, sendo também imaginária por propor um sentido para o real; seu caráter fundamental é o de ser expressão e não dissimulação do real; e principalmente que a expressividade das imagens opera de maneira estética e hermenêutica, porque nossa relação afetiva com o mundo se constitui de imagens que também nos permite interpretar as coisas e a nós mesmos.

A partir disso, abordamos a ampliação da dimensão estética que, junto ao alargamento da dimensão hermenêutica, parece apontar para uma nova forma de lidar com as imagens no cenário contemporâneo. Qual seja, tratase de um modo de estar no mundo pelo qual podemos experimentar tanto a ausência de sentido (dado trágico do real) como a multiplicidade de sentidos possíveis (imaginário).

\section{Estatuto epistemológico da imagem}

Aristóteles é o primeiro filósofo a sistematizar, depois das abordagens iniciais de Platão, uma teoria sobre a imagem em seu Sobre a Alma, quando

Filosofia e Educação [rfe] - volume 8, número 1 - Campinas, SP

Fevereiro-Maio de 2016 - ISSN 1984-9605 - p. 7-25 
a define "como sensações, só que sem matéria" (Aristóteles, Sobre a Alma, III, 8, 432a, 10). Para o filósofo grego, a imagem é um produto da imaginação e esta é "racional ou perceptiva" (III, 10, 433b, 29). Nessa perspectiva, a imagem ou é percepcionada ou é imaginada, mas "as sensações são sempre verdadeiras, enquanto as imagens são maioritariamente falsas" (III, 3, 428a, 12), o que inaugura uma visão desconfiada da imagem e da imaginação, pelo seu potencial de falseamento: “a imaginação não será nenhuma das faculdades que são sempre verdadeiras, como a ciência ou o entendimento. É que a imaginação também pode ser falsa" (III, 3, 428a, 17).

É possível afirmar que tal conceituação do par imagem/imaginação permanecerá essencialmente inalterada por séculos. Rebaixada frente ao entendimento por seu potencial falseador, a imaginação se resumirá à função de imprimir mentalmente a imagem de um objeto ausente, oriundo de uma realidade existente "por baixo" das imagens. Daí a condição secundária da imagem em relação ao objeto percepcionado. Segundo Diógenes (apud Abbagnano, 2007, p. 537), a imagem é “aquilo que é impresso, formado e distinto do objeto existente, que se conforma à sua existência e por isso é o que não seria se o objeto não existisse".

Tal postura filosófica coincide com a iconoclastia bíblica, que proíbe a imagem em numerosas passagens, como no Gênesis, no Êxodo e no Deuteronômio. Não só as imagens de Deus são proibidas, mas também a figura de homem ou mulher, animal, pássaro etc. Também não se deve cultuar as imagens naturais, como o sol, a lua ou as estrelas. Trata-se, portanto, de um Deus ciumento, como aponta Besançon (1997, p. 109), conquanto se trate de um tema complexo e por vezes contraditório, já que o homem foi criado à imagem de Deus e o próprio Cristo seja Deus: “Quem me viu, viu o pai” (apud Besançon, 1997, p. 136) subjaz a ideia de que a 
imagem guarda sempre uma relação inferior à coisa que representa. Assim, a imagem representaria um objeto e operaria por semelhança. Análoga à ideia, a imagem seria tão somente o referente indicativo de um referido concreto. Não constituiria, portanto, um saber, um sentido ou mesmo um conhecimento.

A filosofia moderna não altera fundamentalmente essa compreensão restritiva da imaginação enquanto reprodutora da percepção, persistindo a concepção da imagem como rastro ou vestígio do que é percebido. Para Descartes, "nenhuma das coisas que a imaginação me capacita a entender tem qualquer relevância para o [verdadeiro] conhecimento que possuo de mim mesmo, e, portanto, deve-se, com todo o cuidado, desviar a mente desse modo de conceber as coisas (...)" (apud Cottingham, 1995, p. 83). Para Hobbes, a "imaginação nada mais é que uma sensação enfraquecida ou langorosa por estar distante do seu objeto" (apud Abbagnano, 2007, p. 538).

No século XX, simultaneamente à redefinição dos limites da razão e da crítica ao racionalismo, a imagem e a imaginação passam a ser admitidas por seu potencial (em vez de desvio) epistemológico. A mudança de paradigma, no entanto, é lenta e muitas concepções ainda veem a imaginação com desconfiança, como é o caso de Lacan, que compreende o imaginário como o lugar do engodo, da ilusão (apud Roudinesco; Plon, 1998, p. 371).

O caso de Jean-Paul Sartre é mais complexo, pois ele acaba por sucumbir a uma visão a que, inicialmente, quer se opor. Assim, em $A$ Imaginação, traça como objetivo ultrapassar as concepções clássicas que reduzem a imagem a uma representação. Essa ontologia ingênua, que é como Sartre batiza essas abordagens, considera a imagem "uma coisa, tanto quanto a coisa da qual é a imagem. Contudo, pelo fato mesmo de ser imagem, recebe uma espécie de inferioridade metafísica em relação à coisa 
que ela representa. Em suma, a imagem é uma coisa menor" (Sartre, 2008, p. 10). E defende: "a imagem é um certo tipo de consciência. A imagem é um ato e não uma coisa. A imagem é consciência de alguma coisa" (p. 137).

Entretanto, sua defesa fenomenológica da imaginação requer a descrição da estrutura "imagem", que intenta levar a cabo no livro $O$ Imaginário, obra que contradiz A Imaginação, pois contrapõe o imaginário ao real: "o tipo de existência do objeto imaginado na medida em que é uma imagem difere em natureza do tipo de existência do objeto apreendido como real" (Sartre, 1996, p. 235). De modo que a condição para uma consciência "formar imagens" é "colocar uma tese de irrealidade" (p. 238). Assim, o elogio do imaginário pretendido por Sartre termina por desvalorizá-lo, como observa Gilbert Durand ao criticar sua concepção de imagem como "apenas uma degradação do saber, uma apresentação de um quase-objeto, remetendo-a assim à insignificância” (Durand, 1997, p. 29).

Tal perspectiva iconoclasta do Ocidente sustenta que o "raciocínio socrático e seu subsequente batismo cristão, além de desejar ser considerado, e com muito orgulho, o único herdeiro de uma única Verdade, quase sempre desafiou as imagens" (Durand, 1998, p. 7). Base diferente é a das civilizações não-ocidentais, que "estabeleceram seu universo mental, individual e social em fundamentos pluralistas, portanto, diferenciados" (idem). Como consequência, esse "politeísmo de valores" - expressão que Durand resgata de Max Weber - é iconófilo, receptivo tanto às imagens quanto aos ídolos, o eidôlon grego.

O problema central da imagem na tradição ocidental é, portanto, epistemológico. A lógica, a razão, o raciocínio suplantaram o poder cognitivo da imagem. Nem mesmo os avanços técnicos que permitiram a produção e reprodução desenfreada de imagens - caso da fotografia e do cinema - foram suficientes para reverter essa situação, ao menos não 
inicialmente. Como aponta Teixeira Coelho (2004, p. 206), "muitos consideram e consideraram o cinema, desde os tempos de Griffith, como a vitória da 'desinformação concisa', do 'simulacro de pensamento': um livro pensa mas um filme não". Sabemos que hoje - principalmente depois dos trabalhos de Deleuze sobre o cinema - não é mais assim. "Os grandes autores de cinema nos pareceram confrontáveis não apenas com pintores, arquitetos, músicos, mas também com pensadores. Eles pensam com imagens-movimento e com imagens-tempo, em vez de conceitos" (Deleuze, 1985, p. 8).

Um dos responsáveis pela mudança do estatuto epistemológico da imagem é Gilbert Durand, que considera o imaginário como "o conjunto de imagens e relações de imagens que constitui o capital pensado do homo sapiens - (...) como o grande denominador fundamental onde se vêm encontrar todas as criações do pensamento humano" (1997, p. 38). Tal compreensão abrange tudo o que foi criado pelo "pensamento humano", fundindo assim imaginação e razão, pensamento e criação. Mas mais importante que incluir no museu do imaginário tanto as obras artísticas quanto as científicas é conceber "o caráter processual do imaginário. Com efeito, o imaginário se define mais por seu aspecto dinâmico, figurativo, que por sua base estrutural" (Ferreira-Santos \& Almeida, 2012, p. 38).

O próprio Durand (1997) esclarece que os precursores de seus estudos apontaram para o dinamismo organizador presente no símbolo constitutivo da imagem. Dentre tais percursores, Durand (ibidem, p. 29-30) menciona Pradines, que observa que "o pensamento não tem outro conteúdo que não seja a ordem das imagens"; Jung, que viu que "o pensamento repousa em imagens gerais"; Piaget, que apontou para a coerência funcional "do pensamento simbólico e do sentido conceitual"; e, por fim, Bachelard, ao considerar que "a imaginação é dinamismo organizador". Assim, "muito 
longe de ser a faculdade de 'formar' imagens, a imaginação é potência dinâmica que 'deforma' as cópias pragmáticas fornecidas pela percepção, e esse dinamismo reformador das sensações torna-se o fundamento de toda vida psíquica".

Assim, a imaginação deve ser compreendida pelo seu caráter dinâmico. Ela não se subordina à imagem, que pode ser captada pela percepção visual, rememorada ou mesmo idealizada, como nas formas geométricas. Mesmo a percepção, sob esse viés, pode ser vista como derivada da imaginação: ao diferenciar sonhos, fantasias e memórias de uma coisa percebida não fazemos mais do que categorizar imagens que se apresentam a nós, inferindo, a partir de algumas delas e não de outras, uma suposta objetividade ou concretude. A arbitrariedade dessa categorização mostra que as imagens não são índices de alguma coisa que a imaginação consulta para chegar ao entendimento; imagens não são, em suma, algo traiçoeiro que deveria ser sempre julgado em função de qualquer coisa para além dele. Como adverte Durand (1997, p. 59), "partimos de uma concepção simbólica da imaginação, quer dizer, de uma concepção que postula o semantismo das imagens, o fato de elas não serem signos, mas sim conterem materialmente, de algum modo, o seu sentido".

Como materialidade portadora de sentido, a imagem não expressa oposição ao real, na chave da irrealidade sartreana, por exemplo, ou mesmo sua falsificação, na linhagem aristotélica, porque sua relação não é com a verdade do logos, mas com a expressividade da aparência. A imagem presentifica-se indiferente ao jogo da verdade e da ilusão, alheia à qualquer necessidade que não seja a da expressão -daí seu caráter estético, sobre o qual nos debruçaremos a seguir.

Para Clément Rosset (2008), o real não é confrontado pelo imaginário, mas pela ilusão, que o nega, senão in toto, ao menos em parte, mais 
precisamente a parte que nos aparece como "desagradável". A tese defendida pelo filósofo francês é a de que a representação imaginária apresenta todos os ingredientes para se harmonizar com a percepção do real (Rosset, 2008, p. 107).

Essa relação de parentesco entre o real e o imaginário faz com que os termos sejam intercambiáveis: o real é a soma das aparências, das imagens e dos fantasmas que enganosamente sugerem sua existência (Rosset, 2008, p. 68) e o imaginário é o fator de organização do real (Durand, 1997). Isso significa que o real é expresso pelo imaginário que, por sua vez, coleciona representações possíveis do real (Almeida, 2015, p. 79).

Desse modo, o real é dado pela pluralidade de imaginários enquanto a ilusão é a adesão a um único imaginário (o imaginário da Verdade), pretensamente erigido como portador da realidade, mas que efetivamente a nega, justamente por negar o caráter ilusório de toda adesão à versão única tida por verdadeira.

\section{A dimensão estético-hermenêutica das imagens}

Uma vez delineada essa relação de reciprocidade entre real e imaginário, em oposição ao paradigma da irrealidade da imagem, devemos traçar algumas implicações dessa relação com o estatuto epistemológico das imagens. Primeira implicação: toda imagem é real enquanto imagem, sendo também imaginária por propor uma fabulação, um sentido para o real.

Mas o sentido confabulado não seria também real, se é por meio dele que nos instauramos no espaço tangível do mundo? Um átomo seria mais ou menos real? O radar do morcego seria mais ou menos real? Quer dizer, os recursos todos que os organismos dispõem para perceber a realidade não são reais? Haveria, enfim, diferença entre o real de fato e o real percebido como real? 
Não é difícil notar como todas essas separações apenas sobrepõem camadas e mais camadas de categorização do real, sem alterar em nada aquela concepção iconoclasta tradicional, problematizada anteriormente. Separar ou medir "mais real" e "menos real", com efeito, é um recurso imaginário e, não obstante, ilusório (por estabelecer e estabilizar um princípio qualquer que sirva como premissa, comprovante ou amparo para o real).

Essa proposição é aqui imprescindível não só por rejeitar a oposição clássica entre aparência e verdade, mas principalmente por uni-las em oposição à ilusão metafísica de um "mundo verdadeiro", tal como a denunciava Nietzsche (2006, III, §2, p. 26): “O mundo 'aparente’ é o único. O 'mundo verdadeiro' é apenas acrescentado mendazmente”. O elogio de Nietzsche à aparência, pois, coincide com o elogio ao real, pois o espaço da representação e da imaginação não é outro senão o lugar em que se encontra o real ${ }^{1}$. Decorre daí uma segunda implicação ao estatuto das imagens: seu caráter fundamental é o de ser expressão e não dissimulação do real, de ser aparência como potência positiva, e não como contraparte negativa de um suposto real que estaria por trás dela.

De um lado, a imaginação é uma interação constante com o mundo por meio dela criamos conceitos, traduzimos objetos, estipulamos ordens diversas e acreditamos ou duvidamos delas -; de outro, mesmo traduzido e retraduzido, o real permanece intraduzível, isto é, sempre sem um sentido além de ser ele mesmo. Uma árvore será sempre “árvore” (imaginário), mas uma árvore nunca é a mesma que outra (real). Nada há entre uma coisa e outra que não seja construído, estruturado, formalizado e ritualizado socialmente sob a forma de convenção (que, sendo imaginária, é também

\footnotetext{
1 “Abolimos o mundo verdadeiro: o que restou? O aparente, talvez?... Não! Com o mundo verdadeiro abolimos também o mundo aparente!” (Nietzsche, ibidem, §6, p. 32).
} 
real).

A questão é que ao imaginário cabe menos alterar o real do que, antes, fazê-lo "falar" por meio de algum sentido e algum afeto. Em outros termos, as imagens transitam entre dois registros: o estético, pois são indissociáveis de nossa relação afetiva com o mundo, e o hermenêutico, ${ }^{2}$ à medida que, por meio delas, situamo-nos no real, atribuindo alguma interpretação às coisas e a nós mesmos. Analisemos, em primeiro lugar, seu aspecto estético-afetivo.

Por afeto compreendo as afecções do corpo, pelas quais sua potência de agir é aumentada ou diminuída, estimulada ou refreada, e, ao mesmo tempo, as ideias dessas afecções. Assim, quando podemos ser a causa adequada de alguma dessas afecções, por afeto compreendo, então, uma ação (Spinoza, 2007, III, def. 3, p. 98).

De acordo com Spinoza, conhecer o mundo significa imaginar o que somos a partir de nossa inserção no mundo. É preciso considerar que, para o filósofo barroco, a mente (ou "espírito") não existe apartada do corpo, porque ela é a ideia que o corpo faz de si mesmo. Ou seja, a mente "se imagina" enquanto corpo. Trata-se, portanto, da tradução (em termos de conceitos e imagens) das muitas maneiras pelas quais nosso corpo pode afetar e ser afetado pelo mundo. Por conseguinte, nossa inserção no mundo se dá por meio de imagens e afetos: imaginamos as coisas na medida em que elas nos afetam, e o modo como nos "afetamos" pode aumentar ou diminuir nossa potência de agir no mundo.

"Potência de agir" resulta de uma escolha que, por meio das imagens, tomamos a todo instante: aprovar uma existência sem princípio ou finalidade que não de ordem imaginária, ou, não suportando tal visão, valer-

2 "[...] a hermenêutica é a teoria das operações da compreensão em sua relação com a interpretação dos textos" (Ricoeur, 2008, p. 23). 
se de uma ilusão qualquer que "eufemize" tal existência em prol de um sentido consolador (Almeida, 2015, p. 75-76). Só que mesmo a tentativa de escapar de uma realidade desagradável por meio de uma ilusão imaginária conduz justamente a essa mesma realidade (porque ela é, afinal, a única existente).

O que está em jogo na imaginação, com efeito, é o modo particular como conhecemos nossos afetos e, com isso, intensificamos ou enfraquecemos nossa relação com o mundo, nossa vontade de viver. Saber, por exemplo, que a vida é finita, mas permeada de paixões, sofrimentos e alegrias, pode intensificar nossa vontade de viver. Em contrapartida, se ignoramos o fato de que o conhecimento é também afetivo (sendo nada mais que a maneira pela qual o corpo se relaciona com o mundo), essa mesma potência de agir pode diminuir em prol de valores tidos como "independentes" do corpo e seus afetos.

Pensadas então de modo inerente ao "viver a vida" - potencialmente como obra de arte, nos termos nietzschianos ${ }^{3}$-, as imagens adquirem especial relevância estética, ao menos numa concepção ampla: do grego aisthesis ou aestesis, estética significa a capacidade de sentir o mundo, compreendê-lo pelos sentidos, como exercício das sensações. Doravante abordaremos outros aspectos desse registro estético das imagens; antes disso, resta-nos elucidar o registro hermenêutico que as imagens também abrangem.

Se o mundo pode ser visto, sentido e vivido, também pode ser interpretado. O que implica expressá-lo, traduzi-lo e narrá-lo para compreender não tanto o mundo em si, mas o sentido que o "faz falar", ou seja, nossa relação com este mundo - "compreender a si compreendendo o mundo", nos termos de Paul Ricoeur (2008, p. 69). Não se trata,

${ }^{3}$ Cf. Nietzsche, 2001, § 299.

Filosofia e Educação [rfe] - volume 8, número 1 - Campinas, SP

Fevereiro-Maio de 2016 - ISSN 1984-9605 - p. 7-25 
evidentemente, de uma dimensão separada da estética; pelo contrário, o aspecto hermenêutico das imagens remete à noção spinozista de "expressão": não a manifestação de uma essência, no léxico aristotélico, mas somente um modo particular de ser, afetar-se e compreender o mundo. ${ }^{4}$

Embora não se possa "escolher", por exemplo, sofrer ou alegrar-se, a interpretação subsequente nos possibilita orientar nossas experiências no sentido de eleger certas fruições, de optar por determinadas disposições em detrimento de outras, de investir nesse ou naquele afeto já vivido. Mais precisamente, as imagens operam na esteira de uma "hermenêutica trágica":

[...] se tudo pode ser interpretado, é precisamente porque não há o que ser interpretado - sendo um dos aspectos do trágico "o que se furta a toda tentativa de interpretação" [Rosset].

Isso não implica, contudo, que se recuse a interpretar e, portanto, que se invalide a hermenêutica. A recusa do pensamento trágico não concerne ao ato de interpretar ou às interpretações produzidas, mas tão somente que haja algo a ser interpretado, isto é, um significado, uma ordem, um conteúdo inerente ao real. Com efeito, por "hermenêutica trágica" devemos entender apenas uma hermenêutica que, como a de Ricoeur, não pressupõe um conteúdo específico a ser interpretado, mas que, em vez disso, encare o compreender como um modo-de-ser - uma vez que "o trágico falado é preferível ao trágico silencioso" [Rosset] (Beccari, 2015, p. 101).

Disso resulta a seguinte implicação: qualquer imagem só faz sentido à medida que é imaginada por alguém e em determinada ocasião. Num mundo como aparência de si, traduzido por sentidos que o expressam pluralmente e por meio dos quais nos inserimos nele, não há o que se ver "por trás" das ${ }^{4}$ Cf. Deleuze, 1968. 
coisas vistas. Caso tal imanência das imagens não esteja em primeiro plano, perdemos de vista a reciprocidade entre o real e o imaginário e logo acatamos uma ilusão qualquer. Isso fica claro quando alguém decreta, por exemplo, que o consumo e os constructos da indústria cultural jamais podem levar a uma "vida autêntica", uma vez que tais elementos nos oferecem imagens prontas, inautênticas, que nos alienam das relações de dominação que os ordenam.

Quem determina qual é a imagem verdadeira e a mentirosa, a mais autêntica e a menos alienante? A resposta é dada por autores como Pierre Bourdieu (2007), em seu livro $A$ distinção ${ }^{5}$ - caso exemplar da moral ascética do esclarecimento, cujo princípio básico é o de ignorar as diferenças interpretativas em prol de um sentido fixo que se coloca "acima" de outros sentidos. Bem diferente é o argumento de Deleuze (2012), em sua conferência $O$ que é um ato de criação?: tanto criar quanto assimilar, traduzir e compreender são expressões de um "gosto", de sensações, de impulsão ou repulsão, sendo a experiência estética uma constante na relação criativa do homem com o mundo.

Ocorre que essa relação criativa não é apenas estética, mas também hermenêutica, por envolver (junto aos gostos e sensações) mediações, interpretações, traduções: "Compreender assemelha-se a traduzir na mesma proporção em que ler um gesto, um texto ou uma imagem implica conferirlhe sentido. A compreensão decorrente das leituras de mundo (suas traduções) é um ato de interpretação" (Almeida, 2015, p. 137). Nossa relação com o mundo está pautada por esse processo simultaneamente

\footnotetext{
${ }^{5}$ A noção reducionista de Bourdieu de que o "gosto", sendo parte do habitus, nada mais é do que a incorporação inconsciente de certos modos de ser que caracterizam uma classe social, suscita-nos de imediato a questão: essa desconfiança de que nenhum gosto escapa dos jogos de dominação, bem como a vontade ulterior de desmistificar todas as convenções, não corresponderia também a uma convenção imaginária, a outro tipo de "distinção"?
} 
estético e hermenêutico, porque é sempre no registro do imaginário que conhecemos nossos afetos e forjamos um sentido para as ocasiões, para nós mesmos e para o mundo.

\section{Imagem estética? Um panorama contemporâneo}

A busca de sentido, o logos, a razão, o conhecimento manifestamse hoje como forma e formulação estética. Relação de gosto, a estetização contemporânea marca o retrocesso do pensamento como indicador de verdade, como referência e referente de um referencial e um referido externos ao próprio conhecimento, um princípio qualquer que transcendesse e permitisse seu salto. Preso em si mesmo, o pensamento não morre nem desaparece: torna-se estético (Almeida, 2015, p. 5).

A partir do século $\mathrm{XX}$, vemos o vasto desenvolvimento de uma estética não mais limitada ao estudo da arte e do belo. À dimensão estética foram atribuídos um alcance e uma importância cada vez maiores, abrangendo territórios que lhe eram tradicionalmente fechados: a difusão da cosmética, do esporte e da moda mostra que a preocupação por um aspecto agradável é muito mais comum do que a apreciação pela salvação da alma ou pelas escolhas políticas. De modo geral, já não é novidade para as pessoas o peso adquirido dos elementos estéticos na formação dos discursos e nas relações sociais.

Por conseguinte, são muitos os pensadores contemporâneos (como Bauman, Lipovetsky e Finkielkrault) que denunciam uma "estetização do mundo" - consumismos, espetacularização, narcisismo - como sintoma de um vazio existencial, de um modo de vida decadente. Mas o denunciam, é claro, em nome de um "valor maior", de uma experiência "verdadeira" que 
lamentavelmente estaria ausente no mundo. Ou seja, assim como aderimos aos sentidos, aos gostos, às imagens, advêm da mesma esfera imaginária certas convenções que por vezes operam como gramática ou instituição reguladora dos gostos - como se a experiência estética fosse restrita a determinados espíritos esclarecidos.

Só que não é apenas a ampliação da estética enquanto campo de estudo, em paralelo ao progressivo esgotamento das definições restritivas da arte $^{6}$, que tem incomodado alguns sábios contemporâneos, mas também o alargamento da dimensão hermenêutica: se nunca antes o conhecimento esteve tão disseminado e acessível, a "verdade" se torna uma questão de interpretação, de opinião. Para Vattimo (1996), ${ }^{7}$ por exemplo, o mundo converteu-se em interpretação e, com isso, perdemos o mundo verdadeiro: esvaziamento de sentido, niilismo consumado, enfraquecimento do pensamento. Ora, se há alguma coisa que esteja se esvaziando ou se ausentando, não é o mundo (verdadeiro ou não), e sim certos imaginários, como o da razão emancipadora e da reflexão crítica. Em contrapartida, outros imaginários ganham força ou tornam-se mais visíveis: o da estetização, o da espetacularização, o da "imagem estética".

É nesse movimento que a ideia de um "mundo verdadeiro", como insistia Nietzsche (2006) em O crepúsculo dos ídolos, torna-se a maior ilusão de todas: liberada da originalidade, a vida cotidiana não mais se subtrai de um modelo ideal, mas se intensifica nos mínimos gestos, na manipulação casual das aparências, no espetáculo fugaz de ver e ser visto. De que modo uma fotografia seria menos original do que o mundo visto? Em que medida um documentário é mais real do que um filme de super-

\footnotetext{
${ }^{6}$ Cf. Favaretto (2011).

7 “[...] a generalização da noção de interpretação, até coincidir com a mesma experiência do mundo, é realmente o resultado de uma transformação no modo de conceber a verdade que caracteriza a hermenêutica como koiné [idioma comum]" (Vattimo, 1996, p. 16).
} 
heróis? Uma vez que as pessoas já sabem do aspecto "fantasioso" daquilo que as entretém, por que continuam a se entreter?

Se tudo o que vemos somente adquire sentido ao ser compreendido, resulta vã a pretensão de ir além das imagens: fingimento que se sabe fingido, aparências que nada têm a esconder. No fluxo cotidiano, pois, a escolha não mais se dá entre a verdade e a mentira, mas entre uma imagem que se vende como verdade e, cada vez mais indistinguível desta, uma imagem que é dada como imagem. Deduzir a partir daí que tudo está se tornando mais "falso" implica a exigência de uma contraparte "verdadeira" - como vemos em Jean Baudrillard (1991), cuja avaliação depreciativa do simulacro reduz todos os gostos e estilos de vida contemporâneos a uma alienação generalizada, um esvaziamento do sentido e um desejo desesperado de camuflar este esse vazio.

É por isso que o estado contemporâneo da estética - deslocado da arte para a vida - pode favorecer a desfabulação do mundo: todas as narrativas, discursos, instituições e boas intenções perdem o estatuto de verdade e se proliferam como ficções às quais aderimos sem crença. O mundo desfabulado mostra-se nu, sem duplo, sem transcendência, sem finalidade ou necessidade (Almeida, 2015, p. 186-187).

$\mathrm{Na}$ experiência desestabilizadora do simulacro, as pretensas verdades mostram-se como ficções, formas, imagens. O simulacro não pretende ser algo além daquilo que é, aparência de mundo, mas expõe e potencializa esse caráter de aparência. Por conseguinte, o que nos liga aos propósitos, aos discursos e mesmo às instituições é menos uma questão racional, lógica, funcional e mais uma questão convencional, estética, formal. Em nossa atual relação com as imagens, portanto, parece ser a forma que prevalece sobre o 
significado: penso que alguma coisa vai acontecer num dado momento, mas a forma como essa coisa acontece ou deixa de acontecer "reconfigura" meu pensamento sobre ela.

Forma como facies, figura, species, aquilo que se liga ao aspecto, à passagem dos sinais, dos gestos, dos movimentos. Enquanto os significados são elementos sempre abstratos, podendo ser tomados como "verdade" a qualquer momento, a forma é, bem ao contrário, aquilo que consolida uma imagem, portanto inseparável dos afetos, da própria situação, daquilo que nos é oferecido. Em vez de expressar uma "visão de mundo", o que importa cada vez mais é fazer diferentes modos de olhar expressarem-se uns pelos outros, num processo que é desde sempre ambíguo porque procede por formas que não têm significado senão na própria rede de imagens a que se ligam.

Insistindo neste caráter processual, estético e hermenêutico do imaginário, podemos finalmente compreender que, por meio das imagens, o mundo explicita-se como aparência de mundo, inaugurando um modo de estar no mundo pelo qual podemos experimentar tanto a ausência de sentido (dado trágico do real) como a multiplicidade de sentidos possíveis (imaginário). Esse comportamento orientado ao dado e à ocasião é capaz de ampliar nossa relação com o mundo junto à pluralidade das interpretações, ao vigor do simulacro, à intensidade dos fluxos afetivos. Nas palavras de Nietzsche (2001, § 280), enfim: “Queremos ver a nós mesmos traduzidos em pedra e planta, queremos passear em nós mesmos, ao andar por essas galerias e jardins". 


\section{Referências bibliográficas}

ABBAGNANO, Nicola. Dicionário de filosofia. São Paulo: Martins Fontes, 2007.

ALMEIDA, Rogério de. O mundo, os homens e suas obras: filosofia trágica e pedagogia da escolha. Tese de Livre-Docência. Faculdade de Educação da Universidade de São Paulo, 2015.

ARISTÓTELES. Sobre a Alma. Obras Completas de Aristóteles, v. III, t. I.

Lisboa: Imprensa Nacional; Casa da Moeda, 2010.

BAUDRILLARD, Jean. Simulacros e simulação. Lisboa: Relógio D’Água, 1991.

BECCARI, Marcos. Articulações simbólicas: uma filosofia do design sob o prisma de uma hermenêutica trágica. Tese de Doutorado. Faculdade de Educação da Universidade de São Paulo, 2015.

BOURDIEU, Pierre. A distinção: crítica social do julgamento. São Paulo: Edusp, 2007.

BESANÇON, Alain. A Imagem Proibida: uma história intelectual da iconoclastia. Rio de Janeiro: Bertrand Brasil, 1997.

DURAND, Gilbert. As Estruturas Antropológicas do Imaginário. São Paulo: Martins Fontes, 1997.

DELEUZE, Gilles. Spinoza et le problème de l'expression. Paris: Les éditions de Minuit, 1968.

. Cinema: imagem-movimento. São Paulo: Brasiliense, 1985.

O que é o ato de criação?. In: DUARTE, R. (org.). O belo autônomo: textos clássicos de estética. Belo Horizonte: Autêntica, 2012.

FAVARETTO, Celso. Deslocamentos: entre a arte e a vida. Revista ARS (PPG-Artes Visuais - USP), v. 9, p. 94-109, 2011.

FERREIRA-SANTOS, Marcos. ALMEIDA, Rogério. Aproximações ao Imaginário: bússola de investigação poética. São Paulo: Képos, 2012.

NIETZSCHE, Friedrich. A gaia ciência. São Paulo: Companhia das Letras, 2001.

Filosofia e Educação [rfe] - volume 8, número 1 - Campinas, SP Fevereiro-Maio de 2016 - ISSN 1984-9605 - p. 7-25 
- Crepúsculo dos idolos: como se filosofa com o martelo. São Paulo:

Companhia das Letras, 2006.

RICOEUR, Paul. Hermenêutica e ideologias. Petrópolis: Vozes, 2008.

ROSSET, Clément. Fantasmagorías: seguido de lo real, lo imaginario y lo ilusorio. Madrid: Abada Editores, 2008.

ROUDINESCO, Elisabeth. PLON, Michel. Dicionário de psicanálise. Rio de Janeiro: Jorge Zahar, 1998.

SARTRE, Jean-Paul. O Imaginário: psicologia fenomenológica da imaginação. Trad. Duda Machado. São Paulo: Ática, 1996.

. A Imaginação. Trad. Paulo Neves. Porto Alegre, RS: L\&PM, 2008.

SPINOZA, Baruch. Ética, livro I. Belo Horizonte: Autêntica, 2007.

VATTIMO, Gianni. O fim da modernidade: niilismo e hermenêutica na cultura pós-moderna. São Paulo: Martins Fontes, 1996. 